\title{
De la escena ritual a la teatral en una obra de teatro indígena prehispánico: Rabinal Achí o Danza del Tun ${ }^{1}$
}

\section{From Ritual to Theatre Stage in a Pre-Hispanic Indigenous Drama: Rabinal Achí or Danza del Tun}

\author{
Patricia Henríquez Puentes \\ Universidad de Concepción. Facultad de Humanidades y Arte. Concepción, Chile \\ pathenriquez@udec.cl
}

Resumen • El Rabinal Achí o Danza del Tun es arte escénico fundacional del teatro latinoamericano y clave para el proceso de desarrollo del teatro occidental del siglo XX, en tanto cifra ese momento en el que rito y teatro se contenían mutuamente, es decir, en que el espectáculo se hacía a los ojos de Dios y de los hombres. La propuesta escénica entonces, difuminaba los límites entre el espacio destinado al espectador y al actor; la flor y el canto, es decir, la expresión artística, se ampliaba en el tiempo y el espacio invadiendo todas las esferas de lo social; la comunidad vivenciaba la experiencia de revinculación con la divinidad, reestableciendo el cíclico equilibrio cósmico; el espectáculo operaba como catalizador de una experiencia espiritual y el actor, como su facilitador.

Palabras clave: teatro, rito, flor y canto, escena indígena.

\begin{abstract}
The Rabinal Achí or Dance of the Tun is a founding theatrical play of Latin-American theatre and key for the development process of western theatre during the 20th century; it encodes the moment in which rite and theatre were mutually contained, i.e., in that the spectacle was done for the eyes of God and man. The stage design at the time, blurred the limits between the space destined for the spectator and for the actor; flower and song, i.e., the artistic expression, it was extended in time and space invading all the social spheres; the community underwent the experience of reconnecting with divinity, re-establishing the cyclical cosmic balance; the spectacle operated as a catalyst of a spiritual experience and the actor, as its facilitator.
\end{abstract}

Keywords: theatre, rite, flower and song, indigenous scene.

\footnotetext{
Proyecto núm. 11070076: «Teatro Indígena Prehispánico», financiado por el Fondo Nacional de Ciencia y Tecnología, Fondecyt. Investigador responsable: Patricia Henríquez.
} 
El Rabinal Achí o Danza del Tun, declarada el año 2005 por la UNESCO una de las nuevas Obras Maestras del Patrimonio Oral e Inmaterial de la Humanidad, se inscribe en un período de la historia del México Antiguo en el que predomina una particular interpretación del pensamiento tolteca.

Según los sabios toltecas la vida del hombre se desvanece como un sueño y desgarra como un plumaje de quetzal, en consonancia con el ciclo cósmico de las edades o Soles del mundo que sucesivamente alcanzan cierto florecimiento para culminar en un cataclismo que les pone fin.

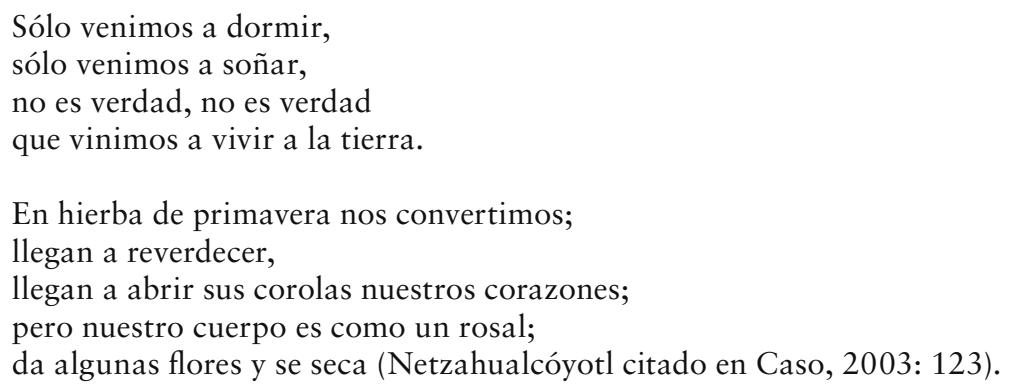

Ante esta perspectiva funesta, los toltecas proponen hacer sabios los rostros y firmes los corazones, a través de la fiesta de la flor y el canto, in xóchitl, in cuicatl, es decir, a través de la expresión artística (Portilla, 2005: 108).

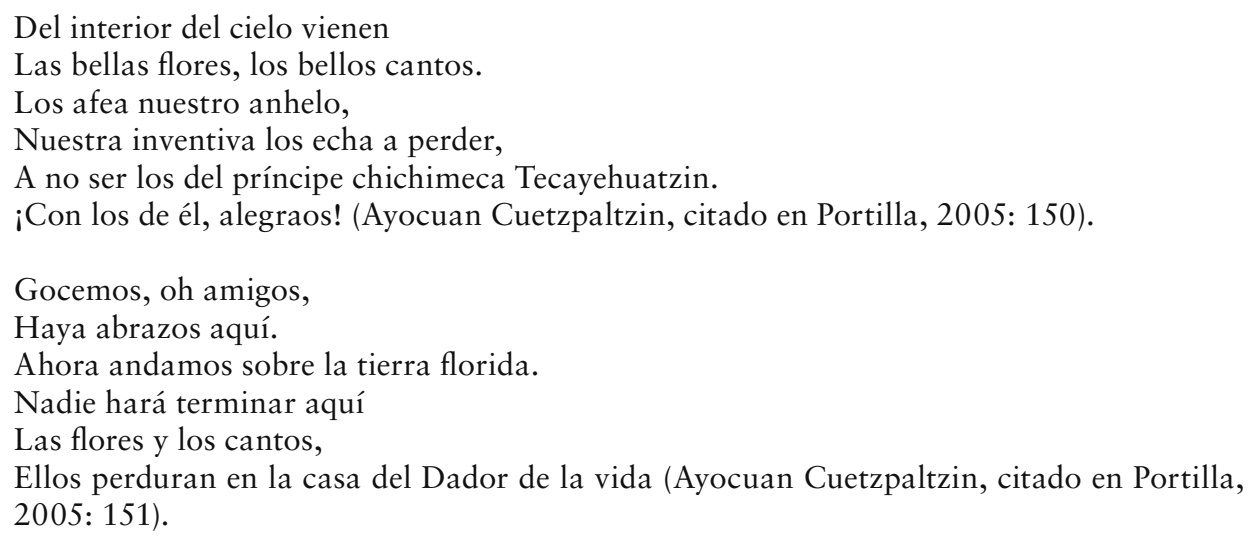

Para las culturas indígenas prehispánicas la sabiduría del rostro, es decir, la fisonomía moral se revelaba en la firmeza del corazón, órgano responsable, desde los primeros días de formación, del movimiento del líquido sagrado que da vida a los hombres y del que simbólicamente provienen las decisiones y consecuentes acciones. El corazón era para las culturas ancestrales el «centro del que parece provenir toda la acción del hombre» (Portilla, 2005: 172).

Se complementaba así entre los nahuas, mejor que entre los mismos griegos, la idea del rostro, con la del dinamismo interior del propio yo. Porque conviene recordar que yól- 
lotl, corazón, etimológicamente se deriva de la misma raíz que oll-in, «movimiento» para significar en su forma abstracta de yóll-otl, la idea de «movilidad», «la movilidad de cada quien» (Portilla, 2005: 172).

Flor y canto es metafóricamente poema, poesía, expresión artística y en general, simbolismo; es el único recuerdo del hombre en la tierra, el camino para encontrar a la divinidad, al Dador de la vida; y el único modo de embriagar los corazones para olvidarse de la tristeza frente a su fugacidad y por sobre todo, para hacerse digno frente a lo inevitable, el tránsito hacia «la región de los descarnados», en busca del principio supremo dual, Ometéotl, divinidad asociada a: Yohualli-ehécatl, «Invisible e Impalpable»; Tloque in Nahuaque, «dueño del cerca y del junto»; Ipalnemohuani, "aquel por quien se vive»; Totecuio in ilhuicahua in tlaltipac-que in mictlane, "nuestro Señor, dueño del cielo, de la tierra y de la región de los muertos»; y Moyocoyani, «el que a sí mismo se inventa» (Portilla, 2005: 109 y Weisz 1994: 152).

El artista náhuatl, verdadero heredero de la tradición tolteca, predestinado para esta importante función por el calendario adivinatorio, Tonalámatl, según el día de su nacimiento, era el que «introducía el simbolismo de la divinidad en las cosas» (Portilla, 2005: 195) y a través de esta acción «endiosada y cuidadosa» (Portilla, 2005: 195), proporcionaba ayuda al hombre para encontrar su verdad, su raíz, para "hacer más sabio su rostro y humanizar su corazón» (Portilla, 2005: 172, 197).

Los aztecas concibieron la posibilidad de posponer el fin de las edades del Sol a través del fortalecimiento de su energía con la sustancia mágica contenida en el líquido precioso que mantiene vivos a los hombres, la sangre, el chalchíuatl; y con el órgano que le da movimiento, el corazón, yóllotl. La sangre simbólicamente es la materialización de la contradicción simbólica del agua y del fuego, representativa del principio vital transpuesto al orden cósmico, contenedora del principio de la vida y redención de la materia. La sangre alimentaba la vida cósmica y la social, que se nutría de la primera (Paz, 1993: 59).

Según esta concepción místico guerrera, el pueblo azteca o pueblo del Sol había sido elegido por la divinidad, Huitzilopochtli, el más pequeño de los cuatro dioses que surgen de Ometéotl, para la máxima empresa de preservar con la sangre de los sacrificios el orden cósmico y posponer el cataclismo final. Quienes se consagraban a la guerra encontraban su raíz en el propósito de convertirse un día en los compañeros de Dios y de otras deidades asociadas a él, con quienes los hombres estaban en perpetua comunicación desde el momento del sacrificio primordial. Los hombres retribuían ese don original, accediendo de esta manera al proceso creador:

La primera cosa que os adornará será la cualidad de águila, la cualidad de tigre, la Guerra Sagrada, flecha y escudo; esto es lo que comeréis, lo que iréis necesitando; de modo que andaréis atemorizando: en pago de vuestro valor andaréis venciendo, andaréis destruyendo a todos los plebeyos y pobladores que ya están asentados allí, en cuanto sitio iréis viendo (Caso, 2003: 119).

He señalado en un estudio de reciente publicación (Henríquez, 2007: 83) que el Rabinal Achi o Danza del Tun figura relaciones de poder del mundo indígena, inscritas en el esquema religioso maya y en una de las prácticas más controvertidas e importantes en el marco de la celebración de sus fiestas religiosas, el rito sacrificial del animal humano, en este caso como resistencia a una forma de agresión, la invasión territorial. El sacrificado en la obra es un cautivo de guerra, aquella inscrita en la lógica de la guerra defensiva. 
cuando tenemos guerra es para darles (a los dioses) de la sangre de los indios que se matan o toman en ella, y échase la sangre para arriba é abaxo é a los lados é por todas partes; porque no sabemos en quál de las partes están, ni tampoco sé si comen o no la sangre ${ }^{2}$ (Citado en Portilla, 2001: 159).

La muerte del cautivo contribuía a mantener el equilibrio cósmico de igual modo a como contribuía a ello la guerra florida, la Xochiyaóyotl, que, tal como lo señala Caso, a diferencia de otras guerras de conquista no tenía por objeto apoderarse de nuevos territorios, ni imponer tributo a los pueblos conquistados, sino procurarse prisioneros para sacrificarlos al Sol (Caso, 2003: 24).

¡Vayamos! Vamos a fortalecer,

A dar fuerza, a prestar apoyo

Al vaso del águila, a la calabaza de nuestro sustento.

¿Acaso habremos de dejar que tenga hambre

El que nos forjó, el que nos inventó?

¡Vayamos! Mostremos cuál es nuestra fuerza ${ }^{3}$ (Citado en Portilla, 2001: 194).

Desde una epistemología telúrica, común a las culturas chamánicas, el territorio era el espacio en el que lo sagrado se manifestaba; las montañas, las flores y las piedras eran consideradas entidades vivas capaces de albergar la sabiduría de los dioses (Eliade, 2002: 34-5 y Weisz, 1994: 169-80). Según esta perspectiva, el espacio no era homogéneo, había en él zonas que se abrían a lo sagrado, es decir, zonas «fuertes» y significativas. La apertura o ruptura de la homogeneidad espacial suponía que el sacerdote o aquellos integrantes de la comunidad especialmente preparados para ello conocían esos espacios fuertes y significativos, desde los cuales por ejemplo, transitaban de una región cósmica a otra (tierra, cielo, inframundo); o pasaban de un orden ontológico a otro (nagualismo o tonalismo) (Eliade, 2001: 25, 31 y 38).

La invasión territorial entonces, era concebida como una desestabilización del equilibrio de la propia vida en la comunidad, en tanto perturbaba los vínculos de cada uno de sus miembros con lo sagrado, especialmente con aquellas zonas en las que la divinidad se revelaba. Según ello, la invasión era en las culturas indígenas prehispánicas castigada inevitablemente con la muerte, vía a través de la cual se restauraba la armonía de la comunidad y reforzaba su unidad social (Girard, 1983: 16).

En el Rabinal Achí el invasor confiesa, ante quien lo ha capturado, haber hundido sus "sandalias en la tierra nueva, antigua» (Rabinal Achi, 1995: 25), es decir, haber tomado posesión de tierras que no le pertenecían. También confiesa haber puesto señales, lo que quiere decir que había modificado los límites de sus tierras. El resultado de esto queda claro desde el Cuadro I.

He aquí que pagarás ahora ese trastorno, bajo el cielo, sobre la tierra.

Tú dijiste, por consiguiente, adiós a tus montañas, a tus valles, porque aquí cortaremos tu raíz, tu tronco, bajo el cielo, sobre la tierra.

Ya no te acontecerá jamás, de día, de noche, bajar, salir de tus montañas, de tus valles.

2 Testimonio proporcionado a Fray Francisco de Bobadilla por el cacique Misésboy.

3 Historia tolteca-Chichimeca, 1942, fol. 42. 
Es preciso que mueras aquí, que desaparezcas aquí, bajo el cielo, sobre la tierra (Rabinal Achí, 1995: 15).

Hay acuerdo entre los investigadores sobre el origen ritual del teatro. Pavis señala que los ritos vinculados a experiencias religiosas reunían a los grupos humanos en torno a un lugar que, simbolizando un espacio sagrado y un tiempo cósmico y mítico distinto del espacio y tiempo profanos, ponía en escena a unos oficiantes que llevaban un vestuario especialmente diseñado y disponían de unos objetos simbólicos para propiciar la revinculación de la comunidad con ese tiempo y espacio primigenios (Pavis, 1998: 405). La escena ritual suponía en este sentido, la presencia de un grupo humano que, demandado en una disposición participativa y de acuerdo a un protocolo, era conducido hacia la ejecución de una partitura de acciones propiciatorias del proceso espiritual de revinculación con alguna dimensión de lo sagrado o con un aspecto del poder divino que irrumpía en el espacio profano (Eliade, 2001: 58-61).

Este acto de revinculación equivalía para el ejecutante del rito, verdadero hacedor de puentes, a un momento de gran intensidad provocada, gracias al cual facilitaba a los testigos el paso a otros estados de conciencia (Grotowski, 1989: 4-5) y de posesión transpersonal o transegoico; ${ }^{4}$ estados a partir de los cuales se disolvían las individualidades y se experimentaba una liberación y una experiencia visionaria. Los cuerpos entonces, se organizaban estéticamente conformando, en el sentido de dar forma, a acciones de personajes de la trama cósmica.

El ejecutante del rito o chamán ha sido definido por los investigadores como un individuo que participa de lo sagrado de manera más completa que otros hombres, era en este sentido, un ser extático (Eliade, 2003: 43). La condición extática del chamán permitía el vuelo de su alma hacia el cielo, la tierra o el mundo subterráneo, entre los muertos, él conocía aquella zona del territorio a través de la cual era posible transitar de un nivel a otro. Durante este trance, su cuerpo moría temporalmente las veces necesarias, para después regresar a la vida (Eliade, 2003: 23).

Los estudiosos señalan que en el espacio de excepción de la escena ritual, el organismo del chamán devenía en un organismo-canal a través del cual las energías espirituales de otros cuerpos circulaban por el suyo y le permitían despojarse de su cuerpo racional para alcanzar un cuerpo mágico y realizar tareas que el primero no podía hacer, como volar, hacerse invisible, percibir cosas a gran distancia y/o transformarse en animal, es decir, experimentar el nagualismo (Weisz, 1994: 97). El chamán tenía, en este sentido, la capacidad para abolir su condición humana profana y retirar a quienes participaban del rito, de su tiempo individual cronológico, histórico, ayudándolos a proyectarse simbólicamente hacia un tiempo sagrado (Eliade, 2002: 47-55. Traducción del autor). En esta escena, los objetos, danzas y cantos rítmicos posibilitaban al chamán la introducción del participante a un tiempo y espacio en el que se marginaba la realidad exterior suplantándola por un espectáculo interno (Weisz, 1993: 56).

La danza, lenguaje del cuerpo en movimiento, organizado estéticamente por la coreo-

\footnotetext{
4 Según Claudio Naranjo todo chamanismo gira en torno a experiencias de trance y posesión (Chile, 2003: 80). Gabriel Weisz sostiene que durante estos estados el individuo está expuesto a la influencia de entidades sobrenaturales que le posibilitan el acceso al desorden de su identidad, es decir, a la salida de sus límites y lo contactan con sus fuerzas psicológicas. El tema del despojo del cuerpo racional, como vehículo de tránsito entre cuerpo normal y cuerpo mágico, es una característica que se encuentra en el esquema religioso de las culturas prehispánicas y por extensión, en las culturas chamánicas (1994: 130-8).
} 
grafía y el canto vocal, ocupaba un lugar fundamental en el desempeño ritual (Polo, 2005: 16. Traducción del autor) y en la preservación de las tradiciones. Danza, música, canto y poesía eran artes inseparables en las culturas ancestrales y fundamentales para la formación del hombre; conformaban un solo arte mayor, en el que ninguna forma artística era enfatizada por sobre otra, sino todas concebidas como una unidad operativa fundamental para facilitar el proceso de desprendimiento corporal y el contacto del hombre indígena con el mundo suprasensible, que exigía forzosamente una concentración preliminar.

La transformación en animal, el nagualismo, era una práctica realizada en el marco del esquema religioso de las culturas prehispánicas (Weisz, 1994: 38). Suponía para quienes la experimentaban la capacidad de entrar en contacto con el espíritu de los animales elegidos y con sus dimensiones sagradas de manera de exteriorizar la entidad anímica del animal representado, el ihíyotl, y actuar ejerciendo poderes. El sacerdote en el nagualismo, se transformaba en otro ser, perdía su forma humana y adquiría una forma animal o vegetal. El nagual era considerado el alter ego animal de cada individuo, definido a partir del tipo y de las características del ihíyotl, es decir del aliento vital que animaba desde dentro del organismo a los animales, incluido al animal humano. Según los investigadores, el ibíyotl se localizaba en el hígado, elli, «donde se concentran los campos de la vitalidad y la afección [...] la cual hace de la persona o del animal un ser brioso, esforzado y valiente» (López Austin, 1980: I, 209).

A diferencia del nagualismo, el tonalismo suponía un destino común entre el hombre y un animal determinado, según el día de nacimiento y por lo tanto, según la posición del individuo respecto del cosmos. El calendario adivinatorio revelaba, a quien estaba habilitado para su lectura e interpretación, el sentido de la conjunción de las fuerzas sobrenaturales y la vida de un ser humano particular. El animal asociado a cada cual equivalía al «tonal». La concepción del tonalismo suponía la exteriorización del tonalli, entidad anímica a la que se debía la vida de los seres humanos, otorgada por el dios supremo, Ometéotl, deidad dual que albergaba una personificación masculina, Ometecubtli, y otra femenina, Omecíhuatl (Weisz, 1994: 150). El tonalli se albergaba en la cabeza, desde el momento de la gestación, lo que hacía que esta zona del cuerpo fuera para las culturas indígenas prehispánicas el punto desde el cual el ser humano establecía un vínculo personal con el mundo de los dioses. Esta entidad anímica salía normal e involuntariamente del cuerpo de todos los seres humanos, durante el sueño, el acto sexual, la ingesta de narcóticos y la enfermedad (Weisz, 1994: 159-64).

En la escena ritual los cuerpos se organizaban estéticamente para restaurar acciones de personajes de la trama cósmica. Estas acciones suponían la coordinación y codificación en el eje temporal de sonidos, y en el eje espacial, de gestos, poses y movimientos (Cardona, 1991: 64). Las acciones restauradas en ambos ejes revelaban las técnicas del cuerpo de la comunidad en la que tenía lugar la práctica ritual y sobre todo, las técnicas a través de las cuales el ihíyotl, el aliento vital, que anima desde dentro el organismo de otro ser o el tonalli, la entidad anímica a la que se debía la vida de cada cual, era exteriorizado por quienes participaban de la escena del rito. Cabe señalar que en el caso de las culturas mesoamericanas estas técnicas operaban en cercano contacto con la naturaleza y el cosmos.

Los investigadores coinciden en que en las culturas ancestrales latinoamericanas los ritmos corporales tendían a la búsqueda de armonía con formas y ritmos pulsativos del cosmos, lo que se revelaba en una cinésica y motricidad que se hacían coextensivas al universo de símbolos y al micro universo simbólico propio de cada comunidad (Castañar, 2005: 1). Luego, también existe acuerdo sobre cierta epistemología telúrica común a los pueblos indígenas latinoamericanos la que se materializaba en técnicas orgánico-corpo- 
rales variadas que, por ejemplo, exploraban en la articulación y compenetración de formas humanas, vegetales y animales. Es importante señalar que estas técnicas revelaban una forma de instalarse en el mundo que no se basaba en la discontinuidad radical entre el mundo humano y el cosmos, sino en el complemento y colaboración de uno con el otro (Sydow, 2004: 41-2). Según esta cosmovisión el hombre forma parte de la naturaleza, haciendo visible la relación-conocimiento que establece con ella, en el propio cuerpo; en tanto entre éste y el cosmos existen características estructurales y funcionales que ambos comparten. En este marco de relación de dependencia mutua, las enfermedades son el resultado de esta interacción y las posibilidades de sanación están vinculadas al reestablecimiento de ambos órdenes, lo que supone la restauración de niveles intermedios como el social (Weisz, 1994: 142; Aranda y otros, 2003: 17).

Los trigonolitos o piedras de tres puntas, piezas usadas por los taínos de las Antillas, aborígenes de Puerto Rico, en ritos agrícolas de carácter propiciatorio, eran objetos sagrados que, representando a Yucahuguamá, el Gran Señor que hacía nacer la yuca, tenían una forma humana provista de zonas en vías de vegetalizarse. Algunas de las piedras de tres puntas figuran un rostro, con ojos, orejas, una boca entreabierta y de exageradas proporciones, como ávida de ingerir substancias nutricias para alimentar la yuca; y en la parte superior de la cabeza, donde para las culturas náhuatl se ubicaba el tonalli, un brote, aparentemente dotado de instinto para abrirse paso hacia la superficie y dirigir la posterior transformación en tronco, ramas y hojas de una nueva planta (Arrom, 1989: 11-23).

Los trigonolitos figuran la articulación y compenetración de la forma humana con la vegetal, como vía de tránsito entre el cuerpo normal y el cuerpo mágico, práctica inscrita en el esquema religioso de las culturas prehispánicas y por extensión, en las culturas chamánicas (Weisz, 1994: 34-8). Esta vía de tránsito también podía tomar forma animal y de objetos o fuerzas sobrenaturales y telúricas. Existen trigonolitos que representan figuras zoomorfas, la parte anterior de una rana, la cabeza de aves acuáticas, de manatí, iguanas, tortugas y cotorras.

Es posible suponer que así como en la cultura náhuatl, también en la taína la asociación entre un animal particular y la persona, simbiosis permanente y definitiva, inscrita en el esquema religioso prehispánico, se realizaba momentos después del nacimiento, como parte de un ritual de bautismo. Luego, también es posible suponer que la transformación zoomorfa, al igual que la fitomorfa, implicaban unas técnicas del cuerpo y una partitura de movimientos, una cinésica y una motricidad, que facilitaba a los miembros de la comunidad la exteriorización de las entidades anímicas representativas de la dimensión sagrada de estos animales, plantas, zonas geográficas (montañas, ríos, quebradas, valles, etc.) o piedras. Weisz (1994) señala que para las culturas prehispánicas, las plantas, rocas y animales, tenían efectos desconocidos sobre la conducta humana, los que se canalizaban a través de efectivas vías de comunicación con ciertas zonas del cuerpo.

Tal como ha quedado demostrado anteriormente, en la cultura náhuatl las relaciones entre una cosmovisión y las concepciones del cuerpo se revelaban en el reconocimiento de la existencia de tres entidades anímicas: tonalli, teyolía e ihíyotl, ubicadas en la cabeza, el corazón e hígado, respectivamente. Durante las experiencias extracorporales de trance, en que la atención crítica sobre las actividades cotidianas era suspendida y la realidad exterior, el mundo interior, los sueños y la vigilia, así como el pasado, presente y futuro resultaban intercambiables, estas entidades anímicas se desprendían del cuerpo para contemplarlo y acceder a otros estados de conciencia. Estos estados perceptivos alterados suponían la sensación de poder ver a través de objetos sólidos y percibir cosas a gran 
distancia; cognitivamente, suponían el acceso a un gran volumen de información y la sensación de un conocimiento sin la intervención del pensamiento (Weisz, 1994: 97-101).

En el Rabinal Achí los Guerreros Águila y los Guerreros Jaguares refieren a las dos grandes cofradías guerreras aztecas, la de los Caballeros-Águila y la de los CaballerosJaguares ${ }^{5}$ dedicados más que otros a procurar al Sol su alimento por medio del sacrificio (Caso, 2003: 53). Guerreros Águilas y Guerreros Jaguares amarillos expresan la oposición dual de Sol-luz-vida / Noche-oscuridad-muerte, respectivamente; expresan además, en tanto símbolos, una imagen doblemente semántica. El color amarillo, origen divino del poder de los guerreros águilas y jaguares, califica y enriquece su significación (Portilla, 1995: 38).

Guerreros Águilas y Guerreros Jaguares son los que tienden sobre la piedra de sacrificio al Varón de los Queché, figurando con ello a los sacerdotes que en las ceremonias rituales conducían a los participantes hacia un espectáculo interno capaz de relajar las defensas conscientes y de dar paso a las experiencias subjetivas que se encuentran en los niveles más profundos del trance provocado por la escena del rito sacrificial, «iOh águilas! ¡Oh jaguares! Vengan, pues, a cumplir su misión, a cumplir su deber; que sus dientes, que sus garras me maten en un momento...» (Rabinal Achí, 1995: 71).

Las «doce águilas amarillas, los doce jaguares amarillos» (Rabinal Achí, 1995: 18) son además los personajes en la obra en quienes está depositada gran parte de la partitura de acciones que componen el protocolo del rito sacrificial.

En el Cuadro I del Primer Acto, hacen sonar el Lotz Tun, «el gran tambor de guerra, el gran tambor sagrado o el gran tambor de sangre», y el Lotz Gohom, «el pequeño tambor de guerra, el pequeño tamboril de sangre». Si consideramos que la obra figura uno de los ritos más importantes de las culturas indígenas prehispánicas como el rito sacrificial y que el sonido del tambor simbólicamente se asocia al sonido primordial, origen del ritmo del universo, representación simbólica del trueno, poder de muerte y fecundidad, capaz de facilitar en quienes lo escuchan el contacto con el mundo de los espíritus, es posible concluir que en esta escena el proceso de creación de los personajes Guerreros Águila y Guerreros Jaguares, supone una experiencia de transformación corporal desde una condición normal a una mágica.

En este punto es interesante recordar lo que los investigadores han señalado como una de las características del teatro indígena prehispánico: la «identificación del actor con su papel». En palabras de Horcasitas (2004), éste se poseía a tal grado de su personaje que no sólo llegaba a creerse dios sino que además, los espectadores — según el investigador «los fieles»- lo consideraban un ser dotado de características divinas. Horcasitas no especifica por cuánto tiempo se extendía este proceso en el que el actor y el personaje eran percibidos por los espectadores como uno solo, tampoco qué significaba esto para

\footnotetext{
5 El águila es el símbolo del Sol, es como el dios del cielo, asimilado al rayo y al trueno, es el ave representativa de las fuerzas celestes. Luego, si el águila es el símbolo del sol y éste se relaciona estrechamente con el factor ambiental de la luz que influye poderosamente sobre el sistema generador de la ritmicidad circádica, entonces, el águila es símbolo de luz y por lo tanto, de vida. La ritmicidad circádica regula nuestra temporalidad biológica de acuerdo con un intervalo de veinticuatro horas. Un desorden circadiano, provocado por un descenso de la temperatura y por lo tanto de la luz, explica la susceptibilidad a los cambios de temperatura y la tendencia a la desincronización. El reloj interno o circadiano es un sistema que incorpora signos del exterior y por ello podemos pensar en un lenguaje rítmico, lenguaje que influye sobre la conducta de los seres humanos. En combinación con el jaguar, símbolo de la noche y del inframundo, representativo de la oscuridad-muerte, el águila simboliza el ejército terreno cuyo deber es alimentar al sol y a la luna con la sangre y los corazones del animal humano sacrificado (Chevalier, 1995: 60-6, 601-2; y Weisz, 1998: 31).
} 
la dinámica de las relaciones comunitarias y para el propio actor indígena.

Existe acuerdo entre los investigadores en relación a las experiencias chamánicas y a los estados de posesión que las caracterizan; también existe acuerdo sobre las relaciones existentes entre esos estados y el nagualismo y el tonalismo, a los que antes me he referido brevemente. Si consideramos estos antecedentes, es posible pensar que cuando Horcasitas señala que el actor indígena se "poseía» de su personaje, de alguna manera quiere decir que según unas técnicas ancestrales, el actor se despojaba de su cuerpo normal para exteriorizar el tonalli o dejar ingresar en él ese aliento vital que, según las culturas indígenas, anima desde dentro otro cuerpo y le otorga brío y valentía. Según López Austin, esta energía esencial, el ibíyotl, se encuentra en el hígado, elli, la mayor glándula de nuestro organismo, almacenador de glucógeno y secretador de bilis, agente fundamental de la digestión, del vigor, de la sexualidad y centro neurálgico de las emociones fuertes, especialmente de la ira. Para las culturas indígenas prehispánicas el hígado alojaba a una de las tres almas del cuerpo, el ihíyotl, relacionada con la tierra y las labores agrícolas; de ahí que «labrar la tierra» se decía en nábuatl: elimiqui(n), literalmente, "perjudicar el hígado» (Proyecto Templo Mayor, 2000: 1).

Según lo anterior es posible pensar que el actor indígena, "poseído por su personaje», revelaba en su propia cinesis, motricidad, gestos y voz, una partitura de acciones coherentes con el aliento vital que ingresaba a su cuerpo, en el caso señalado por Horcasitas, con la energía de un Dios específico. De ahí que el espectador interactuaba con el actor "como si fuera» el Dios, al que incluso veía y leía reconociendo y/o rememorando en él un antiguo lenguaje corporal. Es posible afirmar que el actor indígena, tal como lo señala Grotowski (1989: 5) en relación al performer del ritual primario, descubría en sí mismo una corporeidad antigua a la cual estaba unido por una relación ancestral fuerte.

Pareciera ser que ese estado de posesión implicado en el trabajo del actor indígena se prolongaba en el tiempo y en el espacio, atenuando los límites entre arte escénico y vida, tal como lo sugerían los sabios toltecas del siglo XVI. Horcasitas incorpora en su texto un ejemplo que data del siglo XVII, comprobando de esta manera la permanencia de una de las dimensiones más importantes de la poética escénica indígena prehispánica, bastante avanzado el período colonial.

La mayoría de los indios que bailan esta danza son supersticiosos en cuanto a lo que hacen, creyendo que es acto y acción real lo que sólo es una representación danzada. Cuando viví entre ellos era común que el que iba a representar a San Pedro o a Juan Bautista viniera primero a confesarse, diciendo que tenían que ser santos y puros como el santo a quien representaban, e igualmente preparados para la muerte (Horcasitas, 2004: 96).

La atenuación de los límites entre la expresión artística, la flor y el canto y la vida se revelaban además en el proceso de ampliación del espacio y del tiempo de la escena. El teatro indígena prehispánico se construye hasta el día de hoy durante un período de tiempo que fluctúa entre cinco y trece días aproximadamente y cuya espacialización se realiza en un trayecto por ciertos lugares significativos para la comunidad, lo que equivale a decir que se realiza en escenarios múltiples, en una mixtura espectacular que cita procedimientos fundamentales del teatro y de las ceremonias indígenas prehispánicas en una compleja simbiosis con prácticas propias de la religiosidad popular cristiano-occidental.

El Rabinal Achí o Danza del Tun se presenta todos los años en la comunidad de San Pablo de Rabinal de Guatemala, desde el 12 al 25 de enero, durante la fiesta en conmemoración de la Conversión de San Pablo. La obra considera nueve ceremonias previas y posteriores a su puesta en escena, cinco de ellas realizadas en cerros, considerados hasta 
el día de hoy como lugares «fuertes» y significativos en tanto zonas que albergan la sabiduría de los dioses. En estos espacios sagrados, Kajyub, Kambá, Kisintun, Ximbajá y Saqtijel, el elenco, acompañado por su guía espiritual, Mateo Ismalej, y aparentemente por la comunidad, pide permiso a la divinidad para presentar la obra. El protocolo ceremonial consiste en una invocación a los espíritus mayas, enunciada en lengua achí por el guía espiritual, mientras el fuego consume ciertos elementos considerados sagrados como maíz, candelas, azúcar o ajonjolí (Luis Bruzón, 2008: 1).

Los antecedentes indígenas prehispánicos de este proceso de ampliación de los espectáculos en el tiempo y en el espacio se encuentran en las descripciones de cronistas como Durán:

Otras muchas maneras de bailes y regocijos tenían estos indios para las solemnidades de sus dioses, componiendo a cada ídolo sus diferentes cantares según sus excelencias y grandezas, y así muchos días antes que las fiestas viniesen, había grandes ensayos de cantos y bailes para aquel día, y así, con los cantos nuevos, sacaban diferentes trajes (Durán, 1880: 231. Citado en Arrom, 1967: 12).

Durante los días de fiesta, en el siglo XVI y en el XXI, los espacios públicos reorganizan su funcionamiento para dar lugar a un período de excepción en el que se intensifican las relaciones entre las expresiones artísticas y otras esferas de la vida testimoniando, indicando, provocando transformaciones. El arte penetra lo cotidiano, "poduzindo novas perspectivas e modos de se experimentar a existencia e de se lidar cum situacoes de crise ${ }^{6}$ (Sydow, 2004: 44).

El teatro indígena prehispánico propone hasta hoy el establecimiento de una singular relación actor-espectador, según la cual al espectáculo teatral se acude dispuesto a participar activamente, sobre todo porque constituye el momento de la fiesta de la flor y el canto, vía de búsqueda del reestablecimiento de vínculos y de equilibrios con los otros, la naturaleza, la divinidad y el cosmos y por lo tanto, uno de los únicos caminos para fortalecerse espiritualmente. Los antecedentes de esta propuesta datan de tiempos antiguos.

Señala Horcasitas que una de las características del «drama» indígena prehispánico, es la integración del teatro en la vida del espectador. Este, a diferencia del espectador del teatro occidental, colabora de diversas formas con el espectáculo teatral, con su trabajo, con aportaciones monetarias o preparación de comida y/o de vestuario para la fiesta. En este sentido, el espectador participa activamente de las etapas previas y eventualmente posteriores a la puesta en escena e incluso, en el desarrollo de la misma. Señala Garibay que el espectador indígena se vuelve muchas veces actor, en lugar de limitarse a ser espectador (1954: 122). Horcasitas afirma en el Tomo I de su estudio que los descendientes de esclavos negros en Paramaribo de la Guayana Holandesa, presentaban un baile danzado en el que los espectadores, sentados alrededor de los actores, "de pronto" se unían al entusiasmo creciente de los danzantes (Horcasitas, 2004: 34).

La propuesta de integrar drama-espectador se materializaba, tal como en el ejemplo anterior, en la inexistencia de separación entre escenario y sala o en la proposición de un escenario que permitiera al espectador circular libremente. La escena teatral, incluyendo sus cantos y flores, impregnaba la vida en comunidad proporcionando a cada uno de los

6 Produciendo nuevas perspectivas y modos de experimentar y de lidiar con situaciones de crisis. Traducción del autor. 
miembros el camino del simbolismo para encontrar la sabiduría del rostro y la firmeza del corazón.

El individuo que asiste a La danza de Santiago no entra a una sala: llega a una plaza que es el corazón social, religioso y económico de la comunidad. Es probable que ya haya asistido a una misa conectada con la fiesta. La historia del mismo santo que está en el altar de la iglesia puede ser el tema de la danza dialogada que presenciará. El espectador se mueve, circula, al grado que a veces se ve obligado a alejarse unos pasos de los actores para evitar bromas y hasta evitar golpes. Conoce personalmente, no sólo a los otros espectadores, sino a los actores o danzantes. Cuando termina la función no aplaude y se va, sino que se une a los otros miembros de la comunidad, incluyendo a los actores, en otras actividades festivas (Horcasitas, 2004: 89-90).

Es posible suponer que lo que se restaura hasta el día de hoy en Rabinal de Guatemala es una de las dimensiones más reveladoras de la escena de origen, el poder operatorio desencadenado por/en la vivencia escénica, en la cual el arte impregna todas las acciones de la comunidad, instaurando una nueva realidad. En este marco festivo, los actores, verdaderos depositarios de un saber social, de una forma de interactuar con los espectadores contemporáneos y de una retórica corporal arcaica, vuelven a componer en el espacio guatemalteco contemporáneo, gestos, movimientos, danzas, cantos y sonidos que recuerdan a la comunidad ese otro tiempo ancestral, que existiendo o no, reafirma sus creencias.

En el Cuadro II, las doce Águilas amarillas y los doce Jaguares amarillos constituyen las dos grandes cofradías guerreras a las que el Varón de los Queché podría haberse integrado si se hubiese sometido al Jefe Cinco Lluvia, «Aquí hay doce águilas amarillas, doce jaguares amarillos; sus bocas, sus fauces, no están completas; quizás ese valiente, quizás ese varón ha venido a completar unos y otros» (Rabinal Achí, 1995: 39-40).

Luego, en el Segundo Acto, las doce Águilas amarillas y los doce Jaguares amarillos son los guerreros solicitados por el Varón de los Queché y concedidos por el Jefe Cinco Lluvia, para probar su valentía antes de ser sacrificado, "para practicar la esgrima con el hijo de su flecha, el hijo de su escudo, en los cuatro rincones, en los cuatro lados» (Rabinal Achí, 1995: 68).

Es importante recordar en este punto que la práctica sacrificial entre los aztecas se materializaba de distintas formas. Existía el sacrificio ordinario a través del cual la víctima era tendida sobre una piedra, téchcatl, y tomada por brazos y piernas por cuatro sacerdotes de modo que el pecho del prisionero quedara saliente. El quinto sacerdote con un cuchillo de pedernal le daba un golpe en el pecho, metía la mano en la herida y le arrancaba el corazón ofreciéndoselo a los dioses. Aparentemente, el rito sacrificial figurado en la obra correspondería al «sacrificio ordinario».

En la versión del Rabinal Achí o Danza del Tun, publicada por Raynaud el discurso del acotador que finaliza la obra presenta en una construcción oracional de significado pasivo, la escena en la que «supuestamente» tiene lugar el momento culminante del rito sacrificial: «Las águilas y los jaguares rodean al Varón de los Queché: se supone que lo tienden sobre la piedra de los sacrificios, para abrirle el pecho, mientras todos los presentes bailan en ronda» (Teatro Indígena Prehispánico. Rabinal Achí, 1995: 71).

En la versión de Cid Pérez y Martí de Cid, de 1962, probablemente reescritura de la versión de Brasseur de Bourbourg, la acción sacrificial figura descrita en términos generales en un discurso del acotador que al parecer es un "aporte» de los editores: "Águilas y Jaguares rodean al Varón de los Queché, lo tienden en la piedra del sacrificio y le abren el pecho» (Cid Pérez, Martí de Cid, 1964: 198). 
En nota final del texto los editores informan: «Brasseur no explica si las Águilas y Jaguares mímicamente indican que le sacan el corazón a la víctima y se lo muestran al sol y a los cuatro puntos cardinales» (Cid Pérez, Martí de Cid, 1964: 204). Tal como lo he referido en una comunicación anterior (Henríquez, 2007: 84), si consideramos que la práctica del sacrificio fue uno de los ritos indígenas más repudiados por el hombre europeo desde su llegada a este continente, junto al canibalismo ritual y al empleo de sustancias alucinógenas, todas consideradas prácticas demoníacas, se entiende que el texto finalice con una escena en la que el Varón de los Queché invita a Águilas y Jaguares a cumplir con «su deber» y que sea el discurso del acotador el que explicite escuetamente, en un supuesto, la práctica sacrificial.

En este punto es importante recordar que el Rabinal Achi o Danza del Tun es teatro indígena prehispánico que se mantuvo en la memoria de la comunidad a través de tradición oral hasta el siglo XIX, período en el que fue puesto en escritura alfabética por una figura colonial europea, vinculada a la institución iglesia católica. Entre 1850-1855, Brasseur de Bourbourg, cura párroco del pueblo de San Pablo de Rabinal, transcribió el texto al quiché y luego, al francés, apoyado por Bartolo Zis. Posteriormente, en 1862 en París, la obra fue publicada en edición bilingüe, quiché-francés, en la Collection de documents dans les langues indigénes (Arrom, 1967: 14). En 1928, George Raynaud hizo una nueva traducción al francés, a partir de la cual Luis Cardoza y Aragón, escribió en 1930, la primera versión en español, titulándola El Varón de Rabinal, versión que publicó en los Anales de la Sociedad de Geografía e Historia de Guatemala, Año V, tomo VI, núms. 3 y 4. Arrom (1967:14) señala que la edición más conocida de la obra data de 1955, publicada por la Universidad Nacional Autónoma de México.

Es fundamental no olvidar que lo que se ha puesto en escritura ha sido una de las versiones de las historias contadas oralmente durante siglos, cada traducción que se ha realizado hasta el día de hoy, ha sido una nueva versión de la obra original que ha incorporado el conjunto de consignas, presupuestos implícitos o actos de palabra, que están en curso en las lenguas en un momento determinado (Deleuze y Guattari, 1997: 84); y ha puesto en funcionamiento esquemas literarios y juegos del lenguaje de origen y de término diversos. La puesta en escritura del Rabinal Achi o Danza del Tun, como de otras obras teatrales y de testimonios orales, supuso además operaciones que en palabras de Lienhard, tendieron a acercar el discurso indígena al horizonte de expectativas de otro destinatario, no indígena (1998: 10).

Pese a lo anterior y a la atenuación del sentido fundamental de la obra, el sacrificio del prisionero, su figuración se encuentra en los intersticios de la escritura desde el Cuadro I del Primer Acto hasta finalizar con el momento culminante. De igual modo, se encuentra en ellos una propuesta escénica ancestral para la cual la expresión artística, es una de las herramientas más eficaces para explorar en los vínculos entre las experiencias internas y el exterior. Según lo anterior es posible señalar que el teatro indígena prehispánico es arte de resistencia, las estrategias para mantener en el tiempo sus propuestas han permeado eficazmente la cultura letrada (Ostria, 2001: 71-80).

\section{CONCLUSIONES}

La experiencia ritual en sentido ancestral suponía, para las culturas indígenas prehispánicas, una escena, es decir, un lugar y un tiempo en el que un grupo humano se encon- 
traba para restaurar, de acuerdo a una partitura de acciones, un vínculo antiguo. En esta escena, en la que la expresión artística, la flor y el canto, funcionaba como una unidad operativa fundamental y el artista, como el que introducía el simbolismo de la divinidad en las cosas, los cuerpos experimentaban un cambio de estado desde lo profano a lo sagrado, mediado por un complejo proceso de despojo de una dimensión «normal» para pasar a una «mágica». Este proceso habitualmente significaba el despliegue de escenas de trance y posesión a través de las cuales se vivenciaban experiencias cercanas al nagualismo y/o al tonalismo, es decir, experiencias en las que, desde la cosmovisión de las culturas indígenas prehispánicas, el aliento vital que anima desde dentro del organismo a los animales, incluido el animal humano, el ibíyotl, se exteriorizaba en otro cuerpo; o experiencias a través de las cuales la entidad anímica correspondiente a cada cual, el tonalli, se revelaba con mayor o menor intensidad en una partitura de acciones, sonidos, gestos, poses o movimientos.

La escena teatral indígena prehispánica propone desde el siglo XIII una poética en la que el proceso de creatividad espectacular consiste en el descubrimiento en sí mismo de una corporeidad antigua, que explora persistentemente en las alternativas de articulación de una ritmicidad corporal circádica con formas y ritmos pulsativos del cosmos y con sus niveles intermedios, con el que el cuerpo humano posee características estructurales y funcionales comunes. Entre esos niveles intermedios destacan el territorio y todo lo que lo compone, incluyendo la vida en comunidad, es decir, la interacción social.

Es posible suponer que lo que se restaura hasta el día de hoy en Rabinal de Guatemala es una de las dimensiones más reveladoras de la escena de origen, el poder operatorio desencadenado por/en la vivencia escénica, en la cual el arte impregna todas las acciones de la comunidad, instaurando una nueva realidad. En este marco festivo, los actores, verdaderos depositarios de un saber social, de una forma de interactuar con los espectadores contemporáneos y de una retórica corporal arcaica, vuelven a componer en el espacio guatemalteco contemporáneo, gestos, movimientos, danzas, cantos y sonidos que recuerdan a la comunidad ese otro tiempo ancestral, que existiendo o no, reafirma sus creencias.

El arte teatral indígena prehispánico propone el reestablecimiento armónico de la interacción entre el orden corporal y el cósmico. En el Rabinal Achí o Danza del Tun, ese orden se restaura cíclica y simbólicamente a través de uno de los ritos más importantes de la religiosidad indígena prehispánica, el sacrificio del animal humano. Se trata en este caso y desde este punto de vista, de la proposición azteca para posponer el fin de las edades o soles del mundo y atenuar la tristeza del hombre frente a este final inexorable. En los intersticios de esta propuesta se revela una poética escénica en la que, tal como lo he señalado en estudios anteriores, arte y vida no pueden sino estar profundamente imbricados, en tanto el primero, materializado en la flor y el canto, es propuesto como una de las únicas vías para tornar sabio el rostro y firme el corazón, es decir, para trazar una fisonomía moral que se revela en la firmeza del corazón, centro del que parece provenir toda la acción del hombre. De ahí la vigencia del teatro indígena prehispánico y la urgente necesidad de consultarlo obstinada y persistentemente. 


\section{REFERENCIAS}

Aranda, Andrés; Carlos Viesca, Gabino Sánchez, Gabriel Sánchez, Mariblanca Ramos de Viesca y José Sanfilippo. (2003). La materia médica en el Libellus de Medicinalibus Indorum Herbis. Revista de la Facultad de Medicina. Universidad Autónoma de México, UNAM. Vol. 46, núm. 1, enero-febrero, 2003. Obtenido el 27 de junio de 2008 desde <http://www.ejournal.unam.mx/rfm/no46-1/RFM46104.pdf>

Arrom, José Juan. (1989). Mitología y artes prehispánicas de las Antillas. Siglo XXI Editores, México.

(1967). Historia del Teatro Hispanoamericano (Epoca Colonial). México, D.F.: Ediciones de Andrea.

Balázs, B. (1992). La tradición contemporánea: tres modelos y dos situaciones. En El teatro de calle. Técnica y manejo del espacio. Selección de textos Fabricio Cruciani/ Clelia Falleti. México, D.F.: Grupo Editorial Gaceta, S.A.

Bruzón, Luis. (2008). Rabinal. El espíritu de un guerrero. TuAventura: Ciberperiodismo de viajes. Obtenido el 25 de febrero de 2008 desde <http://www.tuaventura.org/ node/584>

Cardona, Giorgio. (1991). Antropología de la escritura. Barcelona: Editorial Gedisa.

Caso. Alfonso. (2003). El Pueblo del Sol. México, D.F.: Fondo de Cultura Económica.

Castañer, Marta. (2005). Cuerpo y Lenguaje no verbal. La cinésica, la motricidad y el balanceo: Hacia una entropía gestual armónica con un discurso integrador. España. RevistaRecre@rte, No3. Junio, 2005. Obtenido el 27 de junio de 2008 desde: <http:// www.iacat.com/revista/recrearte/recrearte03.htm>

Cid Pérez, José y Martí de Cid, Dolores. (1964). Teatro Indio Precolombino. El Güegüence o Macho Ratón. El Varón de Rabinal. Ollantay. U.S.A.: Aguilar.

Chevalier, Jean. (1995). Diccionario de simbolos. Barcelona: Herder.

Deleuze, Gilles y Guattari, Félix. (1997). Mil mesetas: capitalismo y esquizofrenia. Valencia: Pre-Textos.

Eliade, Mircea. (2003). El chamanismo y las técnicas arcaicas del éxtasis. México, D.F.: Fondo de Cultura Económica.

(2002). Imagens e Símbolos. Traducâo S.C.Tamer. Sao Paulo: Martins Fontes Editora.

(2001). O sagrado e o profano. Traducâo por R.Fernándes. Martins Fontes Editora, Sao Paulo.

Garibay, Angel María (ed). 1954. Historia de la Literatura Náhuatl. Segunda Parte. El trauma de la conquista (1521-1750). México, D.F.: Editorial Porrúa.

Girard, René. (1983). La violencia y lo sagrado. Barcelona: Editorial Anagrama.

Grotowski, Jerzy. (1989). El Performer. Máscara. Cuadernos Latinoamericanos de reflexión sobre escenología. Año I N¹.

Henríquez, Patricia. (2007). Teatro maya: Rabinal Achí o Danza del Tun. Revista Chilena de Literatura $\mathrm{N}^{\circ} 70: 79-108$.

Horcasitas, Fernando. (2004). Teatro náhuatl. Epocas Novohispana y Moderna. I. México, D.F.: UNAM.

Lienhard, Martín. (1998). El cautiverio colonial del discurso indígena: Los testimonios. Ed. Pinto Rodríguez. Del discurso Colonial al Proindigenismo. Ensayos de Historia Latinoamericana. Temuco: Ediciones de la Universidad de La Frontera.

López Austin, Alfredo. (1980). Cuerpo humano e ideología. Las concepciones de los antiguos nahuas I - II. México, D.F.: UNAM, Instituto de Investigaciones Antropológicas. 
Naranjo, Claudio. (2003). Entre meditación y psicoterapia. Traducido por José Mullet. Santiago: Comunicaciones Noreste.

Ostria, Mauricio. (2001). Literatura oral, oralidad ficticia. Estudios Filológicos $\mathrm{N}^{\mathrm{o}} 36$ : 71-80.

Pavis, Patrice. (1998). Diccionario del Teatro. Dramaturgia, estética, semiología. Barcelona: Paidós.

Paz, Octavio. (1993) El laberinto de la soledad. Ciudad de México, D.F.: Fondo de Cultura Económica.

Polo, Regina. (2005). Dancas indígenas: arte e cultura, história e performance. Danca da terra. Tradicao, história, linguagem e teatro. Río De Janeiro: Papel Virtual Editora.

Portilla, Miguel León. (2005). Los Antiguos Mexicanos a través de sus Crónicas y Cantares. México, D.F.: Fondo de Cultura Económica.

(2001). El destino de la palabra. De la oralidad y los códices mesoamericanos a la escritura alfabética. México, D.F.: El Colegio Nacional / Fondo de Cultura Económica.

(1995). Historia de la Literatura Mexicana. Período Prehispánico. México, D.F.: Editorial Alambra Mexicana.

Proyecto Templo Mayor. (2000). Mictlantecuhtli, el hígado y el ibíyotl. Obtenido el 27 de junio de 2008 desde <http://archaeology.asu.edu/tm/pages/elhigado.html >

Sydow, Casiano. (2004). Antonin Artaud. Teatro e Ritual. Brasil: ANNABLUME editora. Comunicacao.

Teatro Indígena Prehispánico. (Rabinal Achí). (1995). México, D.F.: Universidad Autónoma de México.

Weisz, Gabriel. (1998). Dioses de peste. Un estudio sobre literatura y representación. México, D.F.: Siglo XXI Editores.

(1994). Palacio chamánico. Filosofía corporal de Artaud y distintas culturas chamánicas. México, D.F.: Col escenología.

(1993). El juego viviente. Indagaciones sobre las partes ocultas del objeto lúdico. Madrid: Siglo XXI Editores.

Recepción: abril de 2008

Aceptación: agosto de 2008 